\title{
Environmental and behavioural factors affecting activity in the intertidal gastropod Hydrobia ulvae
}

\author{
Francis Orvain ${ }^{1}$ and Pierre-Guy Sauriau ${ }^{1, *}$
}

\begin{abstract}
${ }^{1}$ CREMA (CNRS-IFREMER, UMR 10), Centre de Recherche sur les Ecosytèmes Marins et Aquacoles de L'Houmeau, Place du séminaire, B.P. 5, 17137 L'Houmeau, France

*: Corresponding author : Pierre-Guy Sauriau, email address : Pierre.Guy.Sauriau@ifremer.fr
\end{abstract}

\begin{abstract}
:
Laboratory microcosms were used to investigate the mud snail Hydrobia ulvae (Pennant) bioturbation activities and behavioural changes in response to snail density, algal food, sediment moisture content, light regime and water cover conditions. Density-dependent kinetics of bioturbated muddy areas were described by von Bertalanffy equations, which provided reliable estimates of mud surface covering rates by snail tracks ( $\mathrm{m} 2 \mathrm{~h}-1$ snail-1). Snails need a wet habitat to be active either covered by seawater or by moving in fluid layers for low-tide conditions. Light and microphytobenthic biomass, which are less potent to affect snail activity, are positively interrelated to increase covering rates in the tested chl a concentrations within the range of 1-15 $\mu \mathrm{g} \mathrm{g-1.} \mathrm{Experimental} \mathrm{results} \mathrm{suggested} \mathrm{us} \mathrm{the}$ relevance of microphytobenthos migration processes in affecting crawling activities of $\mathrm{H}$. ulvae that appeared to adjust their foraging efforts in response to benthic algal biomass. Behavioural processes of $\mathrm{H}$. ulvae, in terms of floating, crawling, burrowing and inactive snails, were described using a Markov model. Finally, an empirical model based on von Bertalanffy equations was proposed to describe kinetics of sediment covering by snail tracks under the influences of snail density, sediment moisture content, chl a concentrations and the four combinations of presence/absence of light and seawater. This model should provide a base for further development of a hydrosedimentary model to simulate the effects of $\mathrm{H}$. ulvae bioturbation activities on the resuspension of the intertidal cohesive sediment-water interface for various in situ conditions.
\end{abstract}

Keywords: Behaviour; Bioturbation; Environmental factors; Hydrobia ulvae; Intertidal mudflat; Modelling 


\section{Introduction}

The intertidal habitat is subject to a wide range of rhythmically and rapidly varying features of the environment related to tidal and circadian cycles. In response to these environmental variations, changes in behaviour are common in littoral animals (Palmer, 1987) and especially in the gastropod Hydrobia ulvae (Pennant), which is often reported as the dominant inhabitant of estuaries and intertidal mudflats (Barnes, 1981a; Reise, 1985; Sauriau et al., 1989). Hydrobia ulvae is known to show four modes of intertidal activities (Little and Nix, 1976; Barnes, 1981a): 1) "burying activity": the snail lies, buried in a small pit just below the sediment surface; 2) "crawling activity": it crawls across the substratum to feed (in horizontal or vertical plane, in which case this activity was also called "climbing activity"), 3) "floating activity": it floats within the water column, resuspended by tidal currents or suspended beneath the air/water interface in calm conditions (this last process only takes place after "climbing activity") and 4) "sinking activity": it lies inactive on the surface of the sediment. Experimental investigations have suggested that both exogenous and endogenous factors play a part in determining Hydrobia behaviour (Newell, 1962; 1964) as it is the case for other intertidal species (Palmer, 1987). However, studies made by Little and Nix (1976), Barnes (1981a, 1981b and 1986) and Armonies and Hartke (1995) on changes in snail's behaviour in its natural environment contradicted Newell's conclusions as they interpreted intertidal activity in terms of crawling/browsing phase when covered by water and an inactive phase when the substratum dries during low tide. No endogenous rhythm could be highlighted. Nevertheless, Hydrobia activities are not so drastically related to the single presence or absence of water cover, as the circadian cycle also affects the activity rhythm of this mollusc (Barnes, 1981b, 1986). Furthermore, snails do not simply crawl when covered by water or remain inactive during low tide, but their 4 behaviour modes occur simultaneously in 
natural conditions (except "floating activity" during low tide) and their proportions in crawling, burying, inactive and floating activities may change in response to both tidal and circadian cycles.

Studies undertaken to describe Hydrobia species feeding activities reveal even more complex interrelationships in other environmental and/or biological factors. Grain size (Barnes and Greenwood, 1978; Forbes and Lopez, 1989a), chlorophyll a concentrations (Levinton and Lopez, 1977; Jensen and Siegismund, 1980; Lopez and Cheng, 1983; Bianchi and Levinton, 1984; Forbes and Lopez, 1986; Morrisey, 1988), bacteria populations (Lopez and Cheng, 1983; Bianchi and Levinton 1984), snail density (Levinton and Lopez, 1977; Levinton, 1979; Lôpez-Figueroa and Niell, 1987; Morrissey, 1987; Blanchard et al., 2000) and larval trematodes infection (Mouritsen and Jensen, 1994) are the main factors controlling

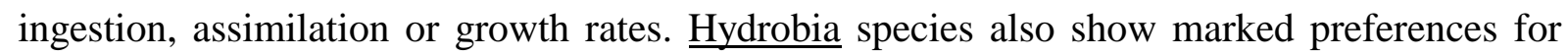
fine sediments (Barnes and Greenwood 1978), for enriched chlorophyll a sediment (Forbes and Lopez, 1986) and they are attracted to light (Newell, 1962). Since Hydrobia species crawling velocity decreases while their feeding rate remains constant (Forbes and Lopez, 1986), these two separate parameters are not subject to environmental conditions in the same way. However, all the aforementioned factors controlling feeding activities could be involved in controlling covering rates and behavioural activities, as snails need to crawl during feeding. Variations in Hydrobia ulvae motile activities could have several implications in the ecology, population dynamics and habitat features of this species. For example, distribution patterns, dispersal and recruitment of the population are directly affected by the occurrence of floating behaviour, and Armonies and Hartke (1995) predicted the routes of dispersal of Hydrobia ulvae by the use of a hydrographic model. Secondary production is also directly affected by all factors influencing crawling and feeding activities (Bianchi and Levinton, 1984; Sola, 1996; Lillebø et al., 1999). 


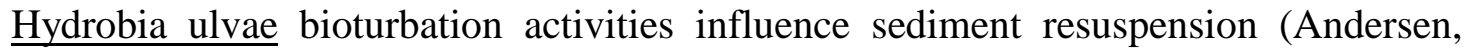

2001) and these activities are directly related to bulk sediment properties and especially sediment moisture content (Orvain et al., in prep.). In an attempt to develop a model simulating variations in bioturbation activities under the influence of sediment properties, we performed several series of experiments to assess 1) the influence of moisture content and other environmental factors (i.e. cover by seawater, presence or absence of light, and chlorophyll a concentrations) on sediment covering rates by snail tracks by measuring crawling kinetics in microcosm experiments and 2) the effect of these factors on behavioural processes by measuring the varying proportions of crawling, burying, inactive and floating snails during the same experiments.

The modelling approach was further performed using the following 3 steps: 1) assuming that the covering of sediment surface by tracks produced by crawling snails is a time- and snail density-dependent process sediment, covering rates were quantified in all experiments by fitting a Von Bertalanffy model to experimental crawling kinetics, 2) a simple Markov model was developed to simulate behavioural processes and variations in proportions of crawling, burying, inactive and floating snails during the same experiments, and 3) the effects of behavioural processes on crawling activities were assessed by testing whether a better fit to experimental crawling kinetics could be obtained by applying correction to include active snail densities that were provided by the behaviour model.

\section{Material and methods}

The whole experimental set followed a five-way factorial design with replication $(\mathrm{n}=3)$, in which snail density, sediment moisture content, chl a concentration, cover by 
99

seawater and presence or absence of light were fixed factors. Due to replication $(n=3)$, tests of

1003 snail densities $\left(1,000,5,000\right.$ and 10,000 snails.m $\left.{ }^{-2}\right), 3$ sediment moisture contents, 2 chl a

101 concentrations (sediment enriched and non-enriched in diatoms) and 2 water cover regimes

102 (with or without water), a total of 108 microcosms were used in 2 experimental sets (with and 103 without light).

104

105

106

107

108

109

110

111

112

\subsection{Experimental procedure}

Mud was collected on the Montportail-Brouage mudflat (Marennes-Oléron Bay), brought back to the laboratory, sieved $(1 \mathrm{~mm})$ to remove macrofauna and homogenised. Full details on the sediment characteristics at the sampled site were in Gouleau et al. (2000). Mud mixture was diluted with sea water (salinity ca. 31\%o), in order to obtain homogeneous sediment moisture content ( $\mathrm{g}$ water/ $\mathrm{g}$ dry sediment $\times 100$ ) of $106 \%, 225 \%$ and $382 \%$. These values are usually found on the Brouage mudflats (Gouleau et al., 2000). Sediment moisture contents were calculated by weight difference between fresh and dried sediment (for 72 hours at $\left.60{ }^{\circ} \mathrm{C}\right)$.

As for diatom-enriched sediment, it was first necessary to isolate the epipelic algae from the mud to form a suspension, which was then added to the sieved sediment. Epipelic diatoms, which are motile microalgae exhibiting an endogenous rhythm of vertical migration were isolated from the mud. The mud was evenly spread in a tray and covered with a $63-\mu \mathrm{m}$ net. After 24-36 hours (at low tide) under artificial light, epipelic diatoms had migrated through the net and accumulated in the net. Diatoms were then collected in sea pre-filtered (GF/F filters) water and diatoms were left to settle for 1 hour. The seawater was then thrown away and the algal suspension was then mixed with sieved sediment and used for adjusting sediment moisture content. 
Microphytobenthos biomass from enriched and non-enriched sediment were assessed using chl a concentrations. Pigments were extracted from freeze-dried sediment in methanol (80\%) for 1 hour in the dark at $4{ }^{\circ} \mathrm{C}$. Fluorescence of the supernatant (after centrifugation)

126 was measured using a Turner Fluorometer and total chl a was calculated according to

127 Lorenzen (1966). Chl a concentrations were equal to 1 and $15 \mu \mathrm{g} \cdot \mathrm{g}^{-1}$ for non-enriched and 128 enriched sediments, respectively.

108 microcosms $(9 \mathrm{~cm}$ in diameter) were filled with prepared mud $(6 \mathrm{~cm}$ in height)

130 and placed in 2 tanks kept in a $17{ }^{\circ} \mathrm{C}$ regulated room. One of the 2 tanks was filled with 131 seawater (salinity ca. 31\%o) and the other tank had no seawater in it, to simulate high and low 132 tide, respectively.

The first experimental set was performed in constant darkness and readings were taken

134 with the aid of a standard white-light torch, the light from which was shown not to affect snail 135 behaviour (Barnes, 1986). The second experimental set was performed with a homogeneous 136 artificial light to avoid a strong source of light that could attract snails and influence their 137 behaviour (Newell, 1962).

138 Crawled areas were measured by two observers over a total period of 24 hours, during 139 which readings were taken at different intervals (after 5, 20, 40 and 60 minutes, thereafter at 140 every hour for 20 hours and finally after 24 hours). Readings were taken frequently at the 141 beginning of experiments, when snail tracks were produced rapidly, but time interval between 142 readings was lengthened at the end of experiments, once whole microcosm areas were 143 bioturbated (i.e. covered by snail tracks). Results were expressed in bioturbated surface 144 relative to the total microcosm surface and maximal values were $100 \%$. Bioturbated surfaces 145 were measured by using an evaluation scale of surface covered by tracks $(1,2,5,10,15,20$, $14630,40,50,75$ and $100 \%$ ). This evaluation scale (Fig. 1) was elaborated with a picture 147 analysis software (IMAGE-IN). 
A number of Hydrobia ulvae were counted on several occasions over the first four hours of experiments (after 5, 10, 20, 30, 60, 120, 180 and 240 minutes). Results were expressed in crawling, floating, sinking and burying snail densities relative to total snail

151 densities. Only microcosms with 5,000 snails.m ${ }^{-2}$ were chosen for these measurements, but all

1523 replicates and 4 other environmental factors were kept in the experimental design to test the

153 influence of environmental conditions on behavioural processes.

\section{2.3. Crawling model development}

155 It was hypothesised that the increase in snail density and activity time would increase 156 the probability that snails create new tracks. Bioturbation kinetics, related to crawled areas 157 (i.e. tracks are called $\mathrm{T}$ in the model and $\mathrm{T}$ is expressed in $\mathrm{m}^{2}$ ), are thus dependent on snail 158 density ( $\mathrm{n}$ in snail. $\mathrm{m}^{-2}$ ), activity time ( $\mathrm{t}$ in hours), individual mud surface covering rate by snail 159 tracks (a in $\mathrm{m}^{2} \cdot \mathrm{h}^{-1} \cdot$ snail $^{-1}$ ) and the probability that a snail meets an old-formed track ( $\mathrm{P}$ no 160 unit).

$$
\frac{d T}{d t}=a \cdot n \cdot(1-\mathrm{P}) \cdot S
$$

162 All notations used in all models are synthesised in Table 2. The individual mud surface 163 covering rate by snail tracks (in $\mathrm{m}^{2} \cdot \mathrm{h}^{-1} \cdot$ snail $^{-1}$ ) will be further called "covering rate" and it is 164 defined as the individual crawling velocities (in $\mathrm{m}^{-\mathrm{h}^{-1}}$ snail ${ }^{-1}$ ) multiplied by the track width (in $165 \mathrm{~m})$.

As experimental crawled areas were expressed relative to the whole surface ( $\mathrm{S}$ in $\mathrm{m}^{2}$ ),

167 we converted crawled areas from $\mathrm{T}$ in $\mathrm{m}^{2}$ to $\phi$ in $\%$ :

$$
\frac{d \phi}{d t}=\operatorname{a.n.}(1-\mathrm{P})
$$

169 The probability that a snail meets an old-formed track during a small time interval $(\Delta \mathrm{t})$ is

170 directly dependent on the surface covered by tracks relative to the total microcosm surface.

171 So, we formulated this probability as follows : 


$$
\mathrm{P}=\frac{T}{S} \quad \text { or } \quad P=\frac{\phi}{100}
$$

173 Consequently, Eq. 2 was transformed into :

$$
\frac{d \phi}{d t}=100 \cdot a \cdot n \cdot\left(1-\frac{\phi}{100}\right)
$$

175 snails, 3) crawling snails and

$$
\phi=100 .\left(1-e^{-\frac{a_{P}}{S} . t}\right)
$$

\subsection{Behaviour Markov model development}

describe population growth (Barnes and Hughes, 1999; Ebert, 1999).

Such a model is classically called a Von Bertalanffy model, which are usually used to Markov models have been used widely in ecology for many decades to describe changing states e.g. the influence of deposit-feeders on the burial and transport of sedimentary particles (Jumars et al., 1981), animal behavioural processes (Castro et al., 1992), animal distribution and settlement (Pineda and Caswell, 1997) and animal migrations (Matis et al., 1992). 
195 transition matrix contains $4^{2}=16$ transition probabilities that snails change in behaviour. This number of probabilities has been reduced by only considering changes in behaviour that really occurred during experiments. All snails were inactive at the beginning and some started crawling crawled $\left(\mathrm{t}_{\mathrm{IC}}\right)$. When animals crawled, some climbed on microcosm slides, where they could reach the air-water interface and float $\left(\mathrm{t}_{\mathrm{CF}}\right)$. Some floating snails fell through the water column and over the sediment where they lay inactive $\left(\mathrm{t}_{\mathrm{FI}}\right)$ before crawling again. On fluid layers, some active crawling snails buried themselves in a small pit $\left(\mathrm{t}_{\mathrm{CB}}\right)$. Other changes in behaviour were not observed when snails were submerged and all corresponding probabilities were nil. So, the state (A) and transition $(\Omega)$ matrix were :

$$
A=\left[\begin{array}{l}
I \\
C \\
F \\
B
\end{array}\right] \quad \Omega=\left[\begin{array}{cccc}
-t_{I C} & 0 & t_{F I} & 0 \\
t_{I C} & -\left(t_{C B}+t_{C F}\right) & 0 & 0 \\
0 & t_{C F} & -t_{F I} & 0 \\
0 & t_{C B} & 0 & 0
\end{array}\right] \quad \quad \frac{d A}{d t}=\Omega . A
$$

The Markovian first-order assumption that transition probabilities only depend on the present state and not on the history of past states that snails have occupied, was respected in this application. The additional Markovian assumption that the transition probabilities remain constant over time may not entirely be satisfied because experimental data revealed that floating snail proportions showed maximal values during the first sequences before falling to equilibrium state. Transition probability that floating snail may lie inactive $\left(\mathrm{t}_{\mathrm{FI}}\right)$, remained low during first sequences and then finally increased to become constant over time. This hypothesis allowed us to consider variations in floating behaviour proportions. A logistic equation in function of activity time was chosen to describe this feature :

$$
t_{F I}=\frac{k_{F I}}{1+e^{-\alpha_{F I}\left(t-t^{0}{ }_{F I}\right)}}
$$

213 where $\mathrm{k}_{\mathrm{FI}}$ is the upper limit of transition probability, $\alpha_{\mathrm{FI}}$ is the rate of increase and $\mathrm{t}_{\mathrm{FI}}^{0}$ is a time 214 constant of integration defining the position of the curve relative to the origin. 
The number of probabilities was reduced for experiments without seawater, because

216 the floating behaviour did not exist in such conditions. Furthermore, some burying snails

217 came back to the air-sediment interface during experiments $\left(t_{\mathrm{BC}}\right)$. In the present case, the 218 model (Eq. 7) was modified as follows :

$$
A=\left[\begin{array}{l}
I \\
C \\
B
\end{array}\right] \quad \Omega=\left[\begin{array}{ccc}
-t_{I C} & 0 & 0 \\
t_{I C} & -t_{C B} & t_{B C} \\
0 & -t_{B C} & t_{C B}
\end{array}\right] \quad \frac{d A}{d t}=\Omega . A
$$

\subsection{Model fitting}

We used an iterative non-linear least squares regression according to Nelder-Mead simplex method to estimate parameter values (Nelder and Mead, 1965). As for Von Bertalanffy and logistic models, differential equations were analytically integrated for computing and minimising. As for the behaviour models, the Markovian matrix were expressed as a system of 4 differential equations, which were integrated numerically using a standard implementation of the fourth-order Runge-Kutta method. As for the Von Bertalanffy models including crawling snail densities rather than total snail densities, all differential equations were integrated numerically using the same method.

The calculations of covering rate values and standard errors were made separately for each replicate $(n=3)$ of crawling kinetics. Analyses of variance of covering rates were performed by using these estimates with the MINITAB software. The variance-covariance matrix of final parameters was calculated using a bootstrap method.

\section{Results}


Crawled areas (Figs. 2 and 3 for respective lit and dark conditions) increased with activity time to converge towards a maximal value of $100 \%$ (i.e. when the total surface was covered by tracks). For cases where kinetics were low, the maximal value was not reached in

241 the 24-hour experimental period. The higher the snail density was, the faster the crawling 242 kinetics were for each experiment (Figs. 2 and 3). Crawling activities were thus time- and 243 density-dependent.

In all experiments (Figs. 2 and 3), kinetics were faster when snails were covered by seawater. Snails were also more active on fluid mud (W=225\% and $\mathrm{W}=382 \%)$ than on compact mud (W=106\%). The other 2 tested factors (i.e. chl a concentrations and light regime) do not seem to affect results as much. However, snails often crawled more slowly on

248 non-enriched sediment than on enriched sediment and more slowly in total darkness than in laboratory-lit conditions. 254 effects and 3) guarantee reliable calculations of covering rates (a in $\mathrm{m}^{2} \cdot \mathrm{h}^{-1} \cdot$ snail $\left.^{-1}\right)$. crawling kinetics seems to follow a logistic curve rather than Von Bertalanffy curves, logistic equation was also tested in our parameter minimisation tests. The formulation of this logistic 258 equation was :

$$
\phi=\frac{100}{1+e^{-\frac{\alpha_{P}}{S}\left(t-t^{P}{ }_{50}\right)}}
$$


260 where $\alpha_{P}$ is the population crawling rate $\left(\alpha_{P}\right.$ in $\left.\mathrm{m}^{2} \cdot \mathrm{h}^{-1}\right)$ and $\mathrm{t}_{50}$ is a constant of integration 261 defining the position of the curve relative to the origin.

Due to the test of 3 snail densities, 3 sediment moisture contents, 2 chl a 263 concentrations, 2 degrees of water cover and 2 light regimes, 72 separate models were 264 adjusted to pools of replicated series of 22 observations $(n=3 \times 22=66)$. For Von Bertalanffy 265 (Eq. 6) and logistic (Eq. 10) models, 72 population covering rates $\left(\alpha_{P}\right.$ and $\left.a_{P}\right)$ were estimated, 266 but for logistic models, an additional set of 72 parameters $\left(\mathrm{t}^{\mathrm{P}}{ }_{50}\right)$ was minimised. Both models 267 provided good fittings with a better accuracy obtained by logistic models $\left(\mathrm{r}^{2}=0.962\right)$ compared 268 to Von Bertalanffy models $\left(\mathrm{r}^{2}=0.943 ; \mathrm{F}_{72,4606}=38.82 ; \mathrm{p}=0\right)$. The results of our present study agreed with those of Lôpez-Figueroa and Niell (1987), 270 in experiments which involved long-term periods (3 days). A direct comparison of our results 271 to their results (Fig. 4) was proposed for experiments in which the combination of 272 environmental conditions was similar (i.e. with 10,000 snails.m ${ }^{-2}$ on the most compact 273 sediment, which was enriched in live or dead diatoms in the presence of light and seawater). 274 We compared fitting Eq. 6 separately to our data series and to their data series (with 275 independent parameter value estimates) to fitting the equation to our data gathered with their 276 data (with a single parameter value estimate). Fitting separate models $\left(r^{2}=0.858\right)$ did not 277 provide a significantly better fit than fitting the gathered series model $\left(r^{2}=0.925 ; F_{1,194}=2.85\right.$; $278 \mathrm{p}=0.092$ ). This result demonstrated that our experimental procedure provided reliable 279 measures that could guarantee satisfactory and similar results irrespective of observers and 280 areas from which snails are taken.

281 Parameters of Eq. 5 were therefore estimated by fitting to experimental results to 282 describe snail density effect. Logistic models were also tested in this minimisation test and 283 Eq. 10 was modified to include the snail density (n) and the individual covering rate $(\alpha)$ as 284 follows: 


$$
\phi=\frac{100}{1+e^{-\alpha . n .\left(t-t_{50}\right)}}
$$

24 parameters (i.e. a expressed in $\mathrm{m}^{2} \cdot \mathrm{h}^{-1} \cdot$ snail $^{-1}$ ) were estimated for Von Bertalanffy models instead of 48 parameters (i.e. $\alpha$ and $t_{50}$ ) for logistic models. Von Bertalanffy models

was yielded by these models compared to logistic models $\left(r^{2}=0.760\right)$. Covering rate estimates with their standard errors are synthesised in Table 2.

Secondly, minimisation tests were performed to establish an equation describing sediment moisture content and chl $\underline{a}$ concentration influences on covering rates and bioturbation kinetics. Covering rate estimates were dressed in function of sediment moisture (i.e. in presence of seawater and light - in presence of seawater and in absence of light - in absence of seawater and in presence of light- in absence of seawater and light). Covering rate variations (Table 2) confirmed influences of environmental conditions on bioturbation kinetics with significant effects of all 4 tested factors (2 four-way ANOVA on lit and dark experiments; $\left.{ }^{*} \mathrm{p}<0.05\right)$. They remained nil whatever the sediment moisture content and chl $\underline{\mathrm{a}}$ concentration when exposed to darkness without seawater and they were also nil for compact mud in lit conditions without seawater, but increased in function of sediment moisture content 302 by following an exponential curve. In lit conditions and in presence of water, covering rates were also higher for diatom enriched sediment. When snails were submerged, covering rates 304 always followed a sigmoid pattern in function of sediment moisture content and their values 305 were lower on a diatom non-enriched sediment in diatoms when exposed to darkness. 306 Sediment moisture content and chl a concentration were included as compound equations in 307 Eq. 5 to simulate their effects on covering rates without modifying snail density and activity 308 time influences (Fig. 5) : 


$$
\phi=100 .\left(1-e^{-a . n . t}\right) \quad \text { with } \quad a=a_{0} . f(w) \cdot g(\text { chla })
$$

310 All constant and parameters of these equations and others are synthesised in Table 1.

312 these variables in our mathematical formulations. The model was thus built on the basis of the

313 analysis of our results, in order to simulate positive influences of sediment moisture content

314 and microphytobenthic biomass. The influence of sediment moisture content on bioturbation

315 activities was assessed by Orvain et al. (in prep.) in terms of resuspended sediment, and

316 especially, in terms of sediment mass (in g. $\mathrm{m}^{-2}$ ) produced by snails within a "biogenic matrix"

317 that is easily resuspended. Such a process can provide tools for finding a reliable

318 mathematical formulation. These experimental results revealed an exponential increase of this

319 amount in function of sediment moisture content within the range of 150-300\%. Since direct

320 mathematical links occur between crawling surfaces and bioturbated sediment mass amount

321 (Orvain, unpublished), we can suggest an exponential expression of covering rates versus

322 sediment moisture content. The f(W) equation compound (in Eq. 12) that represented effects

323 of moisture content for formulation of covering rates, was thus expressed as follows :

$$
f(W)=e^{\gamma W}
$$

325 This equation provides an exponential response of covering rate in function of sediment 326 moisture content and such a response was suitable to describe our results without seawater 327 (Fig. 5a and 5b). However, analysis of results obtained in presence of seawater (Fig. 5c and 328 5d), suggested a sigmoid curve rather than an exponential curve as a plateau was reached for 329 sediment moisture content close to $382 \%$. Hence, Eq. 13 was therefore transformed into a 330 sigmoid equation :

$$
f(W)=\frac{1}{1+e^{-\eta\left(W-W_{50}\right)}}
$$



$\%$ ) than in fluid mud ( $\mathrm{W}=285 \%$ or $\mathrm{W}=382 \%$ ) in high tide experiments, unlike low tide

334 experiments. This complex interaction between sediment moisture content and chl $\underline{\mathrm{a}}$ 335 concentration should appear in the mathematical equation of covering rates. Several combinations of these two variables were tested in several equations in order to perform minimisation tests and to retain the combination, which was the most adjusted to our 338 experimental data:

$$
g(\text { chla })=e^{c h l a^{2 / w}}
$$

340 With a set of 4 independent value parameter estimates $\left(\mathrm{W}_{50}, \lambda, \eta\right.$ and $\left.\mathrm{a}_{0}\right)$ for each case (i.e. in 341 presence of seawater and light - in presence of seawater and in absence of light - in absence 342 of seawater and in presence of light- in absence of seawater and light), both Eqs. 14 and 15 343 yielded good fits to crawling kinetics $\left(r^{2}=0.899\right)$. By searching for a set of commune 344 parameters to fit to all experimental results without reducing the accuracy guaranteed with a 345 set of 4 independent values for each of the 4 parameters too much, we retained a model with 4 346 individual estimates of $\mathrm{W}_{50}$ and $\mathrm{a}_{0}$ and commune estimate of $\lambda$ and $\eta\left(\mathrm{r}^{2}=0.883\right.$; $347 \mathrm{~F}_{6,4734}=128.28 ; \mathrm{p}=0$ ). Parameter estimates are synthesised in Table 3 and the computed results 348 of estimated covering rates versus chl a concentration and sediment moisture content were 349 drawn in Fig. 8. Whatever were the conditions, maximal covering rates were reached for the 350 sediment moisture content ca. $200 \%$.

\subsection{Measurement of behavioural processes}

354 during the experimental period (Figs. 7 and 8 for respective lit and dark conditions). All snails 355 were inactive at the beginning of experiments when we put them in microcosms and they 
reacted more or less rapidly (sometimes within 1 minute), according to whether they found the necessary conditions to make them active. Subsequently, very large proportions of snails crawled at the beginning of the sequence. Flotation, which is an accidental passive event after climbing (Barnes, 1981a), only appeared after this crawling phase, during which they covered 360 the distance to air-water interface. Tendencies of the snails to float were then marked during 361 the first hour of the sequence and, as a result, tendencies of the snails to crawl were inversely 362 marked during the same time. The duration of this floating period was variable according to 363 conditions. Newell (1962) and Barnes (1981a) observed similar patterns for floating snails and 364 for climbing snails, respectively. After this period, proportions of crawling snails increased 365 while proportions of floating snails reduced, until both crawling and floating proportions 366 reached a constant suggesting an equilibrium state.

As obtained for bioturbation kinetics, behavioural activities were affected by variations in the 4 tested environmental factors with interrelated influences. Large proportions of snails 369 crawled when they were in a wet habitat (e.g. when covered by seawater and on fluid layers 370 for low tide experiments). On compact mud (i.e. $\mathrm{W}=106 \%$ ), all snails remained inactive on 371 dried sediments (i.e. without seawater), except in one special case, in which snails were 372 subjected to constant darkness on a chl a enriched sediment. Several authors reported such 373 inactivity, when animals are placed in a dried environment (Newell, 1962; Little and Nix, 374 1976; Barnes, 1981a). Comparison of Figs. 7 and 8 revealed that the influence of light regime is a complex 376 feature: when covered by seawater, much larger proportions of snails crawled when they were 377 exposed to darkness rather than light, except when they were covered by seawater on a chl $\underline{\mathrm{a}}$ 378 enriched sediment, in which case most snails were floating. However, differences in 379 proportions of inactive animals between experiments in the presence or absence of light was not observed when submerged. Influence of light on crawling densities were similar without 
seawater, except in one experiment (i.e. on chl $\underline{\text { a }}$ enriched compact mud) in which animals were more active when they were exposed to constant darkness than laboratory-lit conditions. proportions of active snails increase. Such an influence was not observed when snails were 385 submerged.

\subsection{Behaviour model parameter estimation and variability analysis}

The last step of minimisation tests consisted of the behaviour model development and of testing whether crawling models could be improved by incorporating behavioural

390 processes. $12 \mathrm{t}_{\mathrm{CB}}, \mathrm{t}_{\mathrm{IC}}, \mathrm{t}_{\mathrm{CF}}, \mathrm{k}_{\mathrm{FI}}, \mathrm{t}_{\mathrm{FI}}^{0}$ and $\alpha_{\mathrm{FI}}$ (Eqs. 7 and 8) parameter sets were separately 391 estimated to fit to each of the 12 data series of relative snail numbers for experiments 392 performed with seawater (Figs. 7 and 8). $12 t_{\mathrm{IC}}, \mathrm{t}_{\mathrm{CI}}, \mathrm{t}_{\mathrm{CB}}$ and $\mathrm{t}_{\mathrm{BC}}$ (Eq. 9) parameter sets were 393 separately estimated to fit to each of the 12 data series (with 24 data points) of relative snail 394 numbers for experiments performed without seawater (Figs. 7 and 8). Behaviour models were 395 better fitted for experiments with seawater $\left(r^{2}=0.925\right)$ than without seawater $\left(r^{2}=0.771\right)$.

397 Bertalanffy crawling models (Eq. 4) to include varying crawling snail densities as variables in 398 Eq. 4 instead of total snail densities (n). This correction did not provide a better fit $\left(r^{2}=0.913\right.$ 399 instead of $\left.\mathrm{r}^{2}=0.914\right)$. Corrected individual covering rate estimates are presented with their 400 standard errors in Table 2. Incorporation of behavioural processes always increased crawling 401 snail estimates (Table 2) and variations in the 4 tested factors still affected covering rates in a 402 similar way for both experimental sets with or without light (2 four-way ANOVA on lit and 403 dark experiments, $* * * \mathrm{p}<0.001$ ). No further behaviour model development was performed 
since behavioural processes did not contribute to a significant reduction in the residual sum of squares when fitting Von Bertalanffy models.

\section{Discussion}

effects on crawling kinetics because it was built taking into accounts theoretical backgrounds

412 about probabilities that snails met old-formed-tracks. Since some curves (Figs. 2 and 3) seem to follow a logistic pattern, logistic models were also tested to describe snail density effects and logistic models (Eq. 10) indeed guaranteed better fit than Von Bertalanffy models (Eq. 6) when adjusting to the 72 separate data sets. However, Von bertalanffy models (Eq. 5) were much better adjusted to our experimental data than logistic models (Eq. 11) to include the snail density as a variable in models. Moreover, Von Bertalanffy models have the advantage to include one single parameter (i.e the covering rate) in their equations whereas an additional paramater (i.e. $\mathrm{t}_{50}$ ) is necessary in logistic models.

Blanchard et al. (2000) formulated a random walk model considering behavioural processes in order to simulate the density-dependence of ingestion rate. One of the tested hypotheses was that snails may create mucus tracks which prevent other snails from eating microphytobenthic cells. They rejected this assumption as they found contradictory results to their experimental data. In our present case, the model was developed to simulate bioturbation kinetics, and the latter hypothesis is reliable as old-formed tracks prevent other snails to form new tracks in this local area. For a simplicity's sake, we preferred the Von Bertalanffy analytic model to their random walk model, since this model has been established for parameter 
model, analytic formulation will also allow quick and accurate calculations of covering rates and is thus preferable.

By estimating the snail track width within the range of 500-1000 $\mu \mathrm{m}$ and by using the maximal covering rate ca. $2 \cdot 10^{-4} \mathrm{~m}^{2} \cdot \mathrm{h}^{-1} \cdot$ snail $^{-1}$ (Table 2), we can propose an estimate of 433 individual crawling rate within the range $0.33-0.66 \mathrm{~cm} \cdot \mathrm{mn}^{-1}$. These values are close to those 434 estimated by Mouritsen and Jensen (1994) and Forbes and Lopez (1986) who found individual 435 covering rates equal to $0.5 \mathrm{~cm} \cdot \mathrm{mn}^{-1}$ and $0.2 \mathrm{~cm} \cdot \mathrm{mn}^{-1}$ respectively on submerged fluid 436 sediments with low chl $\underline{\text { a concentrations. }}$

\subsection{Water presence effects}

In our experimental conditions, all snails were active in less than 5 minutes when 440 covered by water, whatever the light regime (Figs. 4 and 5). Without seawater, the 441 probabilities that inactive snails began crawling were directly dependent on sediment moisture 442 content (Figs. 4 and 5). Barnes (1986) concluded that "of the two variables, the absence of 443 light is therefore more potent in influencing activity than is the presence of water cover". In 444 our experiments, water cover and sediment moisture content influences on active snail 445 densities and on covering rates revealed that the presence of seawater is a necessary condition 446 for snails to become active. Chl a concentration and light affected snail activities to a lesser 447 extent by stimulating snails, once they were already active. Barnes (1986) damped the 448 sediment and modified sediment moisture contents while carrying out his experiments. He 449 thus minimised the influence of water presence that should occur in natural low tide 450 conditions. 
As all our experiments, where snails could be active (i.e. for moistened sediments),

454 covering rates were positively influenced by chl a concentrations within the range of 1-15

$455 \mu \mathrm{g} \cdot \mathrm{g}^{-1}$ (Fig. 5). Conversely, Forbes and Lopez (1986) observed a decrease in covering rates

456 versus chl a concentrations within the range of 51-108 $\mu \mathrm{g} \cdot \mathrm{g}^{-1}$. In another study, however,

457 Forbes and Lopez (1989a) found a decrease in locomotion activities with chl a concentrations

458 by comparing sediment processing rates between different silt-clay sediments. Their results of

459 sediment processing rates were 94, 133 and $141 \mu \mathrm{g}$ sediment. $\mathrm{h}^{-1}$ for respective chl $\underline{\mathrm{a}}$

460 concentrations of 68,82 and $202 \mu \mathrm{g} \cdot \mathrm{g}^{-1}$. However, comparison among their experimental

461 results was debatable because sediment and snails were taken from different sites in each case.

462 We could suggest that snails adjust their foraging effort in response to microphytobenthic

463 biomass. Indeed, opposite conclusions between Forbes and Lopez (1986) and us could be

464 interpreted in terms of individual energetic costs and in terms of optimal foraging strategy,

465 which could be different according to food density. A lot of predators and deposit-feeder

466 species react to variations in prey density by increasing their individual feeding activities as

467 their motive activities, until reaching an optimal feeding rate (Holling, 1959; Taghon and

468 Jumars, 1984; Abrams, 1992). According to this theory, animals can decrease their motive

469 activities while maintaining their feeding rate constant for values greater than this threshold.

470 As a result, an increase in relative prey densities entails a gain in net energy gained per day

471 (net gains $=$ gross caloric intake - total daily caloric expenditure), either by increasing

472 consumed energy with an increase in feeding and motive activities or by decreasing losses in

473 energy by reducing motive activities while maintaining the consumed energy constant. Such

474 an assumption, which means that animals are likely to maximise their net intake of energy,

475 either by cost minimising or by maximising energy over the course of each day, depending on

476 diatom biomass, can help us to understand our results which are apparently opposite to Forbes

477 and Lopez's results. Kofoed (1975) showed that energy involved in pedal mucus production is 
478 not negligeable for $\underline{\text { Hydrobia }}$ species and represents $9 \%$ of total assimilated energy. 479 Accordingly, Taghon (1982) developed an optimal foraging model, which predicted that 480 ingestion rates and food values should co-vary positively in order to maximise net time rate of 481 energy gain. Model predictions were supported by experiments performed with three deposit482 feeding polychaete species (Taghon and Jumars, 1984). Our interpretations and data involving 483 crawling activities also support these model predictions. Forbes and Lopez (1989a) demonstrated that feeding rates of microalgal carbon were higher on sand than on silt-clay. Microalgal concentrations were lower in sand than in silt-clay 486 (4 compared to $68 \mu \mathrm{g} \cdot \mathrm{g}^{-1}$ ). They interpreted their results by suggesting that Hydrobia species 487 may have to crawl more on sand in order to meet their daily nutrient requirement since food is 488 less concentrated in coarse sediments. Snails process many more sediments when feeding on 489 sand rather than on silt-clay. This is accomplished by a switch in feeding mode, from particle swallowing to browsing on sediment particles, which become too large to ingest (Lopez and 491 Levinton, 1978; Lopez and Kofoed, 1980; Taghon, 1982). The response of covering rates as 492 regards microphytobenthic biomass thus seems to be totally different when snails crawl either 493 on silt-clay or on sand particles. Both microphytobenthic biomass and particle size are 494 relevant factors that have to be investigated simultaneously to quantify their single and 495 interactive influences on their feeding and crawling activities. Forbes and Lopez (1986) also observed that snails aggregated in chl a enriched 497 patches, where a decrease in covering rates occurred, while feeding rates remained constant. 498 They concluded a snail attraction to diatom patches. We could also have expected such a 499 patch selection to occur in our experiments. However, we observed that more snails crawled 500 onto chl $\underline{a}$ enriched sediments than non-enriched sediments (Figs. 4 and 5) just in one special 501 case (i.e. lit-conditions and in absence of water). This difference was not significant and all other experiments showed that more snails crawled on non-enriched sediments than on 
enriched sediments. Forbes and Lopez (1986) concluded a patch-selection exerted by

504 Hydrobia species, but this might not take place as an attraction to diatom patches, but rather as

505 a direct consequence to a decrease in crawling activities that they observed in patches where

$506 \mathrm{chl}$ a concentrations were very high $\left(108 \mu \mathrm{g} \cdot \mathrm{g}^{-1}\right)$. Assuming that snails slow down in a given

507 area where snail displacements are realised randomly, they will have a natural tendency to

508 aggregate in this given area. Such a hypothesis can be confirmed by using a random-walk

509 model as those developed by Mac Nally (2000) or Blanchard et al. (2000) by considering a

510 decrease in snail mobility in a local area. As we did not observe such a decrease in covering

511 rates induced by increase in chl a concentrations for our experimental conditions, it was thus

512 not surprising that we observed no significant tendencies of snails to aggregate on sediment

513 enriched in chl $\underline{a}$.

515 4.4 Interacted effects of light and microphytobenthic biomass

Differences in covering rates between enriched and non-enriched sediment were more

517 significant for experiments performed with light than without light (Fig. 7) and especially

518 without seawater covering. We can suggest that diatom influence is much exerted in

519 environmental conditions that permit microphytobenthos migration and biofilm constitution

520 i.e. exposed to light and without seawater. Indeed, many deposit-feeders, and especially

521 surface deposit-feeders, feed from a discrete zone of the sediments. In these instances,

522 analysis of a big volume of total mud mixture as an indication of available food particles

523 would be erroneous, because microphytobenthic cells have an endogenous rhythm, based on

524 synchronisation with diurnal periods of emersion, which make them migrate towards sediment

525 surfaces, where they accumulate (Serôdio et al., 1997; de Brouwer and Stal, 2001). When a

526 sediment is taken from an intertidal mudflat, diatoms which live in this sediment, can express

527 their endogenous rhythm after removal of environmental stimuli for ca. 3 days with a 
migratory response decreasing in magnitude (Serodio et al., 1997). The simulating of an

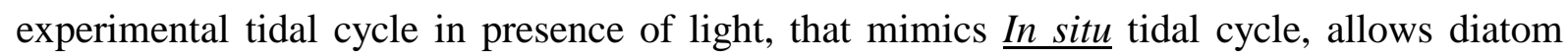

530 migratory rhythm to keep its magnitude and to be prolonged for more than one week

531 (Blanchard et al., 2001). So, we suggest that our experimental conditions allowed diatom 532 patches to appear at air/sediment interface when the sediment was illuminated without 533 seawater rather than for other tested conditions. Without light, diatom positive influence also 534 occurred because chl $\underline{a}$ concentration of the sediment mixture was $15 \mu \mathrm{g} \cdot \mathrm{g}^{-1}$, compared to a 535 non-enriched sediment with a chl $\underline{a}$ concentration equal to $1 \mu \mathrm{g} \cdot \mathrm{g}^{-1}$. However, when snails and 536 sediment were exposed to light, $\operatorname{chl} \underline{a}$ concentrations at sediment surface were likely to be 537 more than $15 \mu \mathrm{g} \cdot \mathrm{g}^{-1}$ and diatom influences were likely to be exacerbated. Diatom 538 concentrations and light are thus 2 factors which are positively interrelated and they increase 539 snail crawling activities.

540 Since the experimental period lasted 24 hours with numerous observations, we can 541 focus on response linearity of covering rates versus activity time to test hypotheses about snail 542 endogenous rhythm, which were formulated by Newell (1962). Several experiments provided 543 suitable kinetics to detail snail activities for the 24-hour total experimental period. Among our 544 experiments with 1,000 snails.m $^{-2}$ (i.e. Figs. 2 j, 2k, 2l, 3d, 3f, 3e and 3j) and with 5,000 545 snails.m ${ }^{-2}$ (i.e. 3 e, 3f, 3j), we observed an increase in snail activity after 5 hours and neither 546 Von Bertalanffy nor logistic models could provide reliable simulation of this pattern (Figs. 2 547 and 3). All experimental conditions were constant during the total experimental period and 548 this could have suggested that snails exhibited an endogenous rhythm, making their covering 549 rates suddenly increase after 5 hours. However, our experiments, where such an increase in 550 activity occurred, were always experiments performed with chl $\underline{a}$ enriched sediment, and we 551 thus suggest that this increase in snail activity was directly related to the presence of diatoms. 552 The occurrence of diatom migratory processes can be evoked once again to explain our 
results, because the $\underline{\text { In situ }}$ diurnal low tide occurred 5 hours after the beginning of our experiments, when the increase in snail activity took place. The fact that more snails crawled after 5 hours provides an alternative explanation to the increase in covering rates. However,

556 we have rejected this alternative hypothesis because the increase in covering rates was 557 observed only for sediments enriched in chl $\underline{a}$ (Figs. 2 and 3), whereas changes in behaviour 558 occurred in all experiments (Figs. 4 and 5). Moreover, including crawling snail densities 559 instead of total snail densities in Von Bertalanffy models (Eq. 5) did not guarantee better fits 560 to crawling kinetics. These increases in crawling activities are thus further evidence of the 561 positive influence of diatoms and of their migratory processes for controlling snail crawling 562 activities. Our interpretations allow us to explain the increase in snail activities without 563 disagreeing with studies that demonstrated that no endogenous rhythm exists for Hydrobia 564 species (Little and Nix, 1976; Barnes, 1981a; 1981b and 1986). Newell (1962) found a direct effect of luminosity on floating snail densities after 15

566 minutes. We found similar results for all sediment moisture content, when the sediment was 567 enriched in $\operatorname{chl} \underline{a}$, but opposite results when sediment was not enriched in chl $\underline{a}$. In light of this 568 additional information, we still insist on the interaction of both microphytobenthic biomass 569 and light to affect snail activity levels.

\subsection{Effects of light}

573 microphytobenthic biomass, do not mean that light influences on covering rates are totally 574 mediated throughout microphytobenthos influences, because light influences were also 575 exhibited for sediment non-enriched in chl $\underline{a}$. Apart from one experiment, where snails were 576 covered by water and sediment was enriched in $\operatorname{chl} \underline{a}$, all our experiments showed that more 
577 snails were active in the light than in the dark (Comparison between Figs. 7 and 8). Barnes

578 (1986) used undisturbed samples to test different combinations of the presence and absence of

579 light and of cover by seawater and we found contradictory results to his, since he concluded:

580 "greater proportion of snails were active in the dark than in the light". E may suggest that, in 581 his experiments, Barnes might have confused light intensity effects with temperature effects

582 because his core samples exposed to light were subject to $\underline{\text { In situ }}$ temperature fluctuations at 583 the same time as luminosity fluctuations. He observed similar fluctuations when sediment was 584 submerged but, to a lesser extent, than when compared to low-tide damp conditions. In these 585 submerged conditions, temperature effects could be amortised, but still occurred to affect their 586 results. Throughout the whole process of our experiments, the temperature was maintained at $587 \quad 17^{\circ} \mathrm{C}$ to ensure that this factor would not affect our results.

\subsection{Behavioural processes}

We also showed that no model improvement can be guaranteed by considering behavioural processes because time-scale involved in crawling kinetics were low (Figs. 2 and 3) compared to time-scale involved in behavioural changes (Figs. 7 and 8). Indeed, most of the inactive snails reacted very rapidly (sometimes within 1 minute) before crawling, whereas

594 increase in crawling rates often appeared after 5 hours. Consequently, variations in crawling snail density are not a relevant factor to explain variations in crawling kinetics.

597 more than one per cent of those on the sediment of $\underline{\text { In situ }}$ conditions and we suggest that

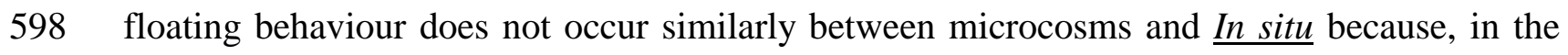
599 latter conditions, "snails do emigrate throughout floating when the tide rises or falls". 600 Similarly, Armonies and Hartke (1995) estimated that only 1 percent of snails float per day. 601 We conclude that environmental factor influences play an important role in crawling and 
602 feeding activities, but that no direct application can be extracted from floating behaviour results. Only crawling activities are relevant criteria for our purposes.

604

\section{Conclusion}

Compared to active or floating snail proportions, crawling kinetics have the advantage

to integrate simultaneously individual and population components on activity levels, as they depend on individual covering rates and on crawling snail densities. Analysis of crawling kinetics and covering rates leads us to conclude the positive influence of sediment moisture content, water cover and light on snail activity levels. Snail mobility increases the probability

611 of encountering the side walls of microcosms with subsequent upward movements and 612 floating and this behaviour thus appears to be an experimental bias due to microcosm confinement. We finally conclude that microcosm floating snail proportions are not a reliable

614 criterion to describe snail activity variations compared to covering rates and these proportions 615 can simply qualitatively confirm previous results obtained from covering rate analysis.

617 changes in ambient environmental conditions, but contrary to his results, our covering rate 618 analysis reveals an exciting single effect of light, which could be positively interrelated to a

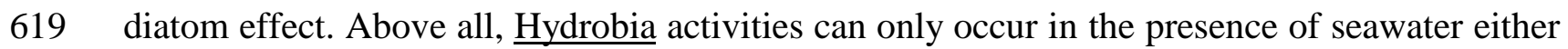
620 by submersion, or by presence of fluid layers in low-tide conditions. We also suggest the 621 relevance of diatom biomass as an interrelated-light variable and suggest that recent findings 622 on microphytobenthos processes (Serôdio et al., 1997; Guarini et al., 2000; Blanchard et al., 623 2001; de Brouwer and Stal, 2001) have to be further investigated to revisit Hydrobia ulvae 624 activities. and we recommend caution to consider single effects of one environmental abiotic variable, 
627 which can be correlated with other confusing variables. Effects of abiotic environmental

628 factors on foraging behaviour must be studied as a whole in evaluating the optimality of

629 foraging behaviour and factors as particle size, diatom biomass, sediment moisture content,

630 cover by seawater, light regime and temperature are all likely to affect snail activity and must

631 be crossed factors into drastic experimental designs to propose a realistic general overview of 632 crawling/feeding activities of intertidal mudflats.

633 The proposed model based on Von Bertalanffy equations includes 10 parameters to

634 describe kinetics of sediment covering by snail tracks under the influence of snail density, 635 sediment moisture content, chl $\underline{a}$ concentrations and the four combinations of 636 presence/absence of light and seawater. The diatom biomass effect should be further 637 reviewed because only $2 \mathrm{chl}$ a concentrations were tested for minimisation tests within a very 638 small range. Furthermore, comparison with other studies (Forbes and Lopez, 1986) suggests 639 to us that Eq. 15 is not reliable for the very high chl $\underline{a}$ concentrations. For further 640 development, our model will also have to be validated by direct confrontation with $\underline{\text { In situ }}$ 641 crawling results reported for wild animals. This would imply some corrections because 642 moderate or severe artefacts may arise from using enclosures that are too small, which could 643 produce inferential nonsense in some circumstances (Mac Nally, 2000).

644 Finally, since Hydrobia bioturbation activities are dependent on environmental factors 645 throughout track formation processes, this model should provide a base for further

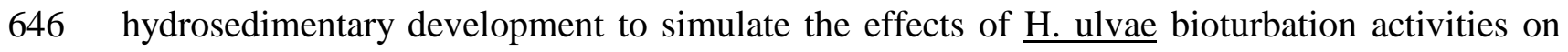
647 the resuspension of the intertidal cohesive sediment-water interface in various In situ 648 conditions. 
649

\section{Acknowledgements}

650

This study has been carried out within the framework of the EU-MAST3 project

651 INTRMUD (MAS3-CT95-0022). The Regional Council of Poitou-Charente and Ifremer have 652 financially supported the study by a doctoral grant awarded to F.O. We are grateful to C.

653 Bacher for invaluable advices in the production of the manuscript and S. Catois for providing 654 help during experiments. 
655

656

657

658

659

660

661

662

663

664

665

666

667

668

669

670

671

672

673

674

675

676

677

678

\section{References}

Abrams, P.A., 1992. Adaptative foraging by predators as a cause of predator-prey cycles. Evol. Ecol. 6, 56-72.

Andersen, T.J., 2001. Seasonal variation in erodability of two temparate, microtidal mudflats. Estuar. Coast. Shelf Sci. 53, 1-12.

Armonies, W., Hartke, D., 1995. Floating of mud snails Hydrobia ulvae in tidal waters of the Wadden Sea, and its implication in distribution patterns. Helgol. Meeresunters. 49, 529-538.

Barnes, R.S.K., 1981a. An experimental study of the pattern and significance of the climbing behaviour of Hydrobia ulvae. J. Mar. Biol. Assoc. U.K. 61, 285-299.

Barnes, R.S.K., 1981b. Factors affecting climbing in the coastal gastropod Hydrobia ulvae. J. Mar. Biol. Assoc. U.K. 61, 301-306.

Barnes, R.S.K., 1986. Daily activity rhythms in the intertidal gastropod Hydrobia ulvae (Pennant). Estuar. Coast. Shelf Sci. 22, 323-334.

Barnes, R.S.K., Greenwood, J.G., 1978. The response of the intertidal gastropod Hydrobia ulvae (Pennant) to sediments of different particle size. J. Exp. Mar. Biol. Ecol. 31, 4354.

Barnes, R.S.K., Hughes R.N., 1999. An introduction to marine ecology, 3rd ed. Blackwell Science, Oxford.

Bianchi, T.S., Levinton, J.S., 1984. The importance of microalgae, bacteria and particulate organic matter in the somatic growth of Hydrobia totteni. J. Mar. Res. 42, 431-443.

Blanchard, G.F., Guarini, J.-M., Orvain, F., Sauriau, P.-G., 2001. Dynamic behaviour of benthic microalgal biomass in intertidal mudflats. J. Exp. Mar. Biol. Ecol. 264, 85100. 
679

680

681

682

683

684

685

686

687

688

689

690

691

692

693

694

695

696

697

698

699

700

701

Blanchard, G.F., Guarini, J.-M., Provot, L., Richard, P., Sauriau, P.-G., 2000. Measurement of ingestion of Hydrobia ulvae (Pennant) on intertidal epipelic microalgae: the effect of mud snail density. J. Exp. Mar. Biol. Ecol. 255, 247-260.

De Brouwer, J.F.C., Stal, L.J., 2001. Short-term dynamics in microphytobenthos distribution and associated extracellular carbohydrates in surface sediments of an intertidal mudflat. Mar. Ecol. Prog. Ser. 218, 33-44.

Castro, K.M., De Alteris, J.T., Milliken, H.O., 1992. The application of a methodology to quantify fish behaviour in the vicinity of demersal trawls in the Northwest atlantic, USA. Proc. Mar. Technol. Soc. Conf. Washington, 310-315.

Ebert, T.A., 1999. Plant and animal populations - methods in demography, 1st ed. Academic Press, San diego.

Forbes, V.E., Lopez, G., 1986. Changes in feeding and covering rates of Hydrobia truncata (Prosobranchia: Hydrobiidae) in response to sedimentary chlorophyll-a and recently egested sediment. Mar. Ecol. Prog. Ser. 33, 287-294.

Forbes, V.E., Lopez, G., 1989a. The role of sediment particle size in the nutritionnal energetics of a surface deposit-feeder. I. Ingestion and absorption of sedimentary microalgae by Hydrobia truncata (Vanatta). J. Exp. Mar. Biol. Ecol. 126, 181-192.

Forbes, V.E., Lopez, G., 1989b. The role of sediment particle size in the nutritionnal energetics of a surface deposit-feeder. II. Energetic cost measured as 14C loss from uniformly $\underline{\text { Hydrobia truncata }}$ (Vanatta). J. Exp. Mar. Biol. Ecol. 126, 193-202.

Gouleau, D., Jouanneau, J.-M., Weber, O., Sauriau, P.-G., 2000. Short and long term sedimentation on Montportail-Brouage intertidal mudflat, Marennes-Oléron Bay (France). Cont. Shelf Res. 20, 1513-1530. 
Guarini, J.-M., Blanchard, G.F., Gros, P., Gouleau, D., Bacher, C., 2000. Dynamic model of the short-term variability of microphytobenthos biomass on temperate intertidal mudflats. Mar. Ecol. Prog. Ser. 291, 291-303.

Holling, C.S., 1959. The components of predation as revealed by a study of small predation of the mammal predation of the european pine sawfly. Can. Entomol. 21, 293-320.

Jensen, K.T., Siegismund, H.R., 1980. The importance of diatoms and bacteria in the diet of Hydrobia-species. Ophelia 1, 193-199.

Jumars, P.A., Nowell, A.R.M., Self, R.F.L. 1981. A simple model of flow-sediment-organism interaction. Mar. Geol. 42, 155-172.

Kofoed, L.H., 1975. The feeding biology of Hydrobia ventros $\underline{a}$ (Montagu). II. Allocation of the components of the carbon-budget and the significance of the secretion of dissolved organic material. J. Exp. Mar. Biol. Ecol. 19, 243-256.

Levinton, J.S., Lopez, G.R., 1977. A model of renewable resources and limitation of depositfeeding benthic populations. Oecologia 31, 177-190.

Levinton, J.S., 1979. The effect of density upon deposit-feeding populations : movements, feeding and floating of Hydrobia ventrosa Montagu (Gastropoda: Prosobranchia). Oecologia 43, 27-39.

Lillebø, A.I., Pardal, M.A., Marques, J.C., 1999. Population structure, dynamics and production of Hydrobia ulvae (Pennant) (Mollusca: Prosobranchia) along an eutrophication gradient estuary (Portugal). Acta Oecol., 20, 289-304.

Little, C., Nix, W., 1976. The burrowing and floating behaviour of the gastropod Hydrobia ulvae. Estuar. Coast. Mar. Biol. 4, 537-544.

Lopez, G.R., Cheng, I.J., 1983. Synoptic measurements of ingestion rate, ingestion selectivity, and absorption efficiency of natural foods in the deposit-feeding molluscs Nucula 
annulata (Bivalvia) and Hydrobia totteni (Gastropoda). Mar. Ecol. Prog. Ser. 11, 5562.

Lopez, G.R., Kofoed, L.H., 1980. Epipsammic browsing and deposit-feeding in mud snails (Hydrobiidae). J. Mar. Res. 38, 585:599.

Lopez, G.R., Levinton, J.S., 1978. The availability of microorganisms attached sediment particles as food for Hydrobia ventrosa (Montagu) (Gastropod: Prosobranchia). Oecologia (Berl.) 32, 263-275.

733

Lôpez-Figueroa, F., Niell, F.X. 1987. Feeding behaviour of Hydrobia ulvae (Pennant) in microcosms. J. Exp. Mar. Biol. Ecol. 114, 153-167.

Lorenzen, C.J., 1966. A method for the continuous measurement of in vivo chlorophyll concentration. Deep-Sea Res. 13, 223-227.

Mac Nally, R., 2000. Modelling confinement experiments in community ecology: differential mobility among competitors. Ecol. Modelling 129, 65-85.

Matis, J.H., Grant, W.E., Miller, T.H., 1992. A semi-Markov process model for migration of marine shrimp. Ecol. Modelling 60, 167-184.

Morrisey, D.J., 1987. Effect of population density and presence of a potential competitor on the growth rate of the mud snail Hydrobia ulvae (Pennant). J. Exp. Mar. Biol. Ecol. $108,275-295$.

Morrisey, D.J., 1988. Differences in effects of grazing by deposit-feeders Hydrobia ulvae (Pennant)(Gastropoda: Prosobranchia) and Corophium arenarium (Amphipoda) on sediment microalgal production. II. Quantitative effects. J. Exp. Mar. Biol. Ecol. 118, 43-53.

Mouritsen, K.N., Jensen, K.T., 1994. The enigma og gigantism: effect of larval trematodes on growth, fecundity, egestion and locomotion in Hydrobia ulvae (Pennant). J. Exp. Mar. Biol. Ecol. 78, 53-66. 
Nelder, J.A., Mead, R., 1965. A simplex method for function minimization. Comput. J. 7, 308-313.

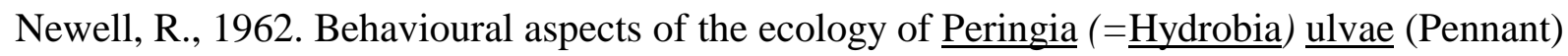
(Gasteropoda, Prosobranchia). Proc. Zool. Soc. Lond. 138, 49-75.

Newell, R., 1964. Some factors controlling the upstream distribution of Hydrobia ulvae (Pennant), (Gastropoda, Prosobranchia). Proc. Zool. Soc. Lond. 142, 85-106.

Orvain, F., Sauriau, P.-G., Bacher, C., Prineau, M., 2001. Quantification of erosive fluxes induced by the bioturbation of the gastropod Hydrobia ulvae on consolidated/ nonconsolidated intertidal cohesive sediments: flume experiments and simple modelling approach. Limnol. Oceanogr. Submitted.

Palmer, J.D., 1987. The biological rhythms and clocks of intertidal animals. Oxford University Press, Oxford.

Pineda, J., Caswell, H., 1997. Dependance of settlement rate on suitable substrate area. Mar. Biol. 129, 541-548.

Reise, K., 1985. Tidal flat ecology. An experimental approach to species interaction. SpringerVerlag, Berlin.

Sauriau, P.-G., Mouret, V., Rincé, J.-P., 1989. Organisation trophique de la malacofaune benthique non cultivée du bassin ostréicole de Marennes-Oléron. Oceanol. Acta. 12, 193-204.

Serôdio, J., da Silva, J.-M., Catarino, F., 1997. Non destructive tracing of migratory rhythms of intertidal benthic microalgae using in vivo chlorophyll a fluorescence. J. Phycol. 33, $542-553$.

Sola, J.C., 1996. Population dynamics, reproduction, growth, and secondary production of the mud-snail Hydrobia ulvae (Pennant). J. Exp. Mar. Biol. Ecol., 205, 49-62. 
775 Taghon, G.L., 1982. Optimal foraging by deposit-feeding invertebrates: roles of particle size and organic coating. Oecologia 52, 295-304.

777 Taghon, G.L., Jumars, P.A., 1984. Variable ingestion rates and its role in optimal foraging 778 behavior of marine deposit-feeders. Ecology 65, 549-558. 
Table 1. Notation used in equations.

\begin{tabular}{|c|c|c|}
\hline $\begin{array}{l}\text { Variables and } \\
\text { parameters }\end{array}$ & Definition and units & Equations \\
\hline \multicolumn{3}{|l|}{ Variables } \\
\hline $\mathrm{S}$ & Total microcosm surface $\left(\mathrm{m}^{2}\right)$ & $1,3,6$ \\
\hline $\mathrm{T}$ & Bioturbated surface (i.e. covered by Tracks) $\left(\mathrm{m}^{2}\right)$ & 1,3 \\
\hline$\phi$ & Bioturbated surface relative to total microcosm surface (\%) & $2,3,4,5,6,10,11$ \\
\hline $\mathrm{n}$ & Snail density (snail. $\mathrm{m}^{-2}$ ) & $1,2,4,5,11,12$ \\
\hline W & Sediment moisture content $(\%)$ & $13,14,15$ \\
\hline $\operatorname{chl} a$ & Sediment Chlorophyll a concentration $\left(\mu \mathrm{g} . \mathrm{g}^{-1}\right)$ & 15 \\
\hline $\mathrm{t}$ & Activity time (h) & $\begin{array}{l}1,2,4,5,6,7,8,9,10 \\
11,12\end{array}$ \\
\hline A & State behaviour matrix & 7,9 \\
\hline I & Inactive snail density (snail.m ${ }^{-2}$ ) & 7,9 \\
\hline $\mathrm{C}$ & Crawling snail density (snail.m ${ }^{-2}$ ) & 7,9 \\
\hline B & Burying snail density (snail. $\mathrm{m}^{-2}$ ) & 7,9 \\
\hline $\mathrm{F}$ & Floating snail density (snail. $\mathrm{m}^{-2}$ ) & 7 \\
\hline \multicolumn{3}{|c|}{ Constant and parameters } \\
\hline $\mathrm{P}$ & Probability that a snail meets an old-formed track & $1,2,3$ \\
\hline a & Covering rate $\left(\mathrm{m}^{2} \cdot \mathrm{h}^{-1}\right.$. snail $\left.\mathrm{l}^{-1}\right)$ in the Von Bertalanffy model & $1,2,4,5,14$ \\
\hline$a^{P}$ & Population covering rate $\left(\mathrm{m}^{2} \cdot \mathrm{h}^{-1}\right)$ in the Von Bertalanffy model & 6 \\
\hline$\alpha$ & Covering rate $\left(\mathrm{m}^{2} \cdot \mathrm{h}^{-1} \cdot\right.$ snail $\left.^{-1}\right)$ in the logistic model & 11 \\
\hline$\alpha$ & Population covering rate $\left(\mathrm{m}^{2} \cdot \mathrm{h}^{-1}\right)$ in the logistic model & 10 \\
\hline $\mathrm{t}_{50}$ & $\begin{array}{l}\text { Constant of integration relative to the covering rate in the logistic model } \\
\text { (h) }\end{array}$ & 11 \\
\hline $\mathrm{t}^{\mathrm{P}}{ }_{50}$ & $\begin{array}{l}\text { Constant of integration relative to the population covering rate in the } \\
\text { logistic model (h) }\end{array}$ & 10 \\
\hline$\Omega$ & Transition behaviour matrix & 7,9 \\
\hline $\mathrm{T}_{\mathrm{ij}}$ & $\begin{array}{l}\text { Probability that a snail that occupied a behaviour pool (i) occupy another } \\
\text { behaviour pool }(\mathrm{j}) \text { during a time interval }\left(\mathrm{h}^{-1}\right) \text {. i and } \mathrm{j} \text { can be all } 4 \\
\text { behavioural modes }\end{array}$ & $7,8,9$ \\
\hline $\mathrm{k}_{\mathrm{FI}}$ & Maximal $t_{F I}$ probability $\left(h^{-1}\right)$ & 8 \\
\hline $\mathrm{a}_{\mathrm{FI}}$ & Rate of increase of $t_{F I}\left(h^{-1}\right)$ & 8 \\
\hline $\mathrm{t}^{50} \mathrm{FI}$ & Constant of integration relative to $t_{F I}(h)$ & 8 \\
\hline $\mathrm{a}_{0}$ & Covering rate when $\mathrm{W} \rightarrow \infty$ and chl $\underline{a}=0 \mu \mathrm{g} \cdot \mathrm{g}^{-1}\left(\mathrm{~m}^{2} \cdot \mathrm{h}^{-1} \cdot\right.$ snail $\left.^{-1}\right)$ & 12,13 \\
\hline $\mathrm{f}(\mathrm{W})$ & $\begin{array}{l}\text { Moisture content dependence compound equation included in the Von } \\
\text { Bertalanffy model }\end{array}$ & $12,13,14$ \\
\hline $\mathrm{g}(\operatorname{chl} \underline{a})$ & $\begin{array}{l}\text { Chl } \underline{a} \text { content dependence compound equation included in the Von } \\
\text { Bertalanffy model }\end{array}$ & 12,13 \\
\hline $\mathrm{W}_{50}$ & $\begin{array}{l}\text { Sediment moisture content dependent parameter in the Von Bertalanffy } \\
\text { model }(\%)\end{array}$ & 14 \\
\hline$\eta$ & Rate of increase of covering rate in function of W(no unit) & 14 \\
\hline$\lambda$ & $\begin{array}{l}\text { Sediment moisture content dependent rate of increase in function of chl } \underline{a} \\
\text { (no unit) }\end{array}$ & 15 \\
\hline
\end{tabular}


Table 2. Covering rate estimates provided by Von Bertalanffy models including total snail densities and crawling snail densities.

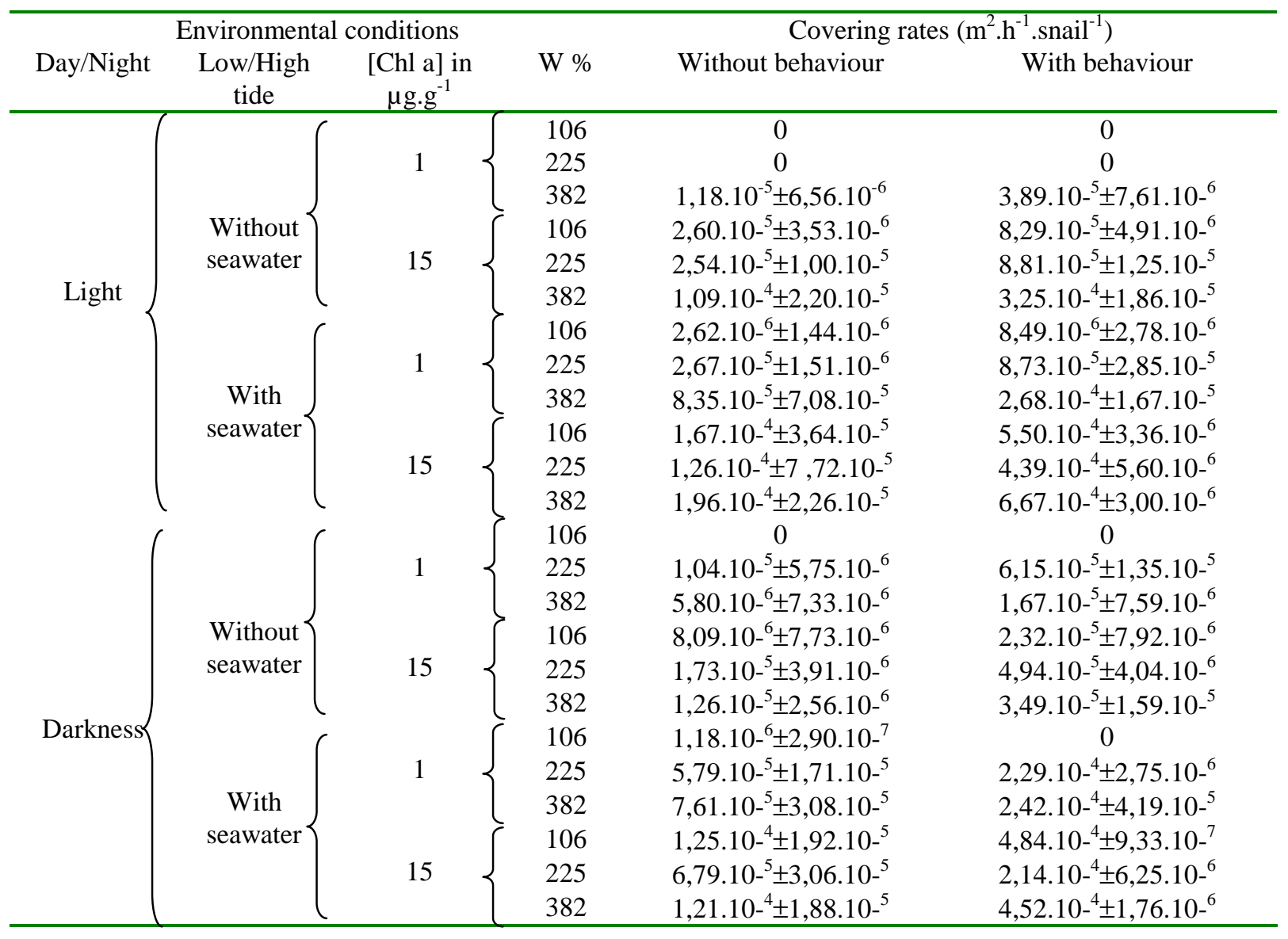


Table 3. Estimates of final model parameters and their standard errors (Eqs. 12, 17 and 18).

\begin{tabular}{|c|c|c|c|c|}
\hline & $a_{0}\left(m^{2} \cdot h^{-1} \cdot\right.$ snail $\left.^{-1}\right)$ & $\mathrm{W}_{50}(\%)$ & $\lambda$ (no unit) & $\eta$ (no unit) \\
\hline $\begin{array}{c}\text { In absence of } \\
\text { seawater and light }\end{array}$ & $2,7.10-{ }^{6} \pm 0,1.10-^{6}$ & $160,3 \pm 1.6$ & & \\
\hline $\begin{array}{l}\text { In presence of } \\
\text { seawater and in }\end{array}$ & $26,6.10-{ }^{6} \pm 1,3.10-^{6}$ & $179,3 \pm 1,6$ & & \\
\hline $\begin{array}{l}\text { absence of light } \\
\text { In absence of } \\
\text { seawater and in } \\
\text { presence of light }\end{array}$ & $15,8.10-{ }^{6} \pm 0,6.10-^{6}$ & $250,0 \pm 1.6$ & $44,3 \cdot 10-^{3} \pm 1.10-^{3}$ & $51,8 \pm 0.8$ \\
\hline $\begin{array}{c}\text { In presence of } \\
\text { seawater and light }\end{array}$ & $42,2.10-{ }^{6} \pm 3,1.10-^{6}$ & $199,8 \pm 4.4$ & & \\
\hline
\end{tabular}




\section{Figure captions}

Fig. 1. Observation scale of tracks covering sediment surface: The real proportions of browsing areas were calculated using IMAGE-IN software.

Fig. 2. Time series of bioturbated areas in microcosms $\left(^{*}\right.$, o and + for 1,$000 ; 5,000$ and 10,000 snails. $\mathrm{m}^{-2}$, respectively) compared to computed results (dashed, full and dotted lines for 1,000, 5,000 and 10,000 snails.m ${ }^{-2}$, respectively) from Von Bertalanffy crawling models fitted to lit-condition experimental results.

Fig. 3. Time series of bioturbated areas in microcosms $(*$, o and + for 1,$000 ; 5,000$ and 10,000 snails. $\mathrm{m}^{-2}$, respectively) compared to computed results (dashed, full and dotted lines for $1,000,5,000$ and 10,000 snails.m ${ }^{-2}$, respectively) from Von Bertalanffy crawling models fitted to dark-condition experimental results.

Fig. 4. Time series of bioturbated areas in microcosms (o) compared to Lôpez-Figueroa and Niell (1987) results $(\times)$ in one experiment $\left(10,000\right.$ snails.m ${ }^{-2}-W=106 \%-[\mathrm{chl} \underline{\mathrm{a}}]=15 \mu \mathrm{g} \cdot \mathrm{g}^{-1}-$ light -seawater cover). Bioturbated areas simulated by using Von Bertalanffy model (full line) were calculated by fitting to both data sets.

Fig. 5. Relationship between covering rate estimates from Von Bertalanffy equations (Eq. 5) versus sediment moisture contents and chl a concentrations.

Fig. 6. Covering rates simulated by using Eqs. 12, 14 and 15 versus sediment moisture contents and chl a concentrations. 
Fig. 7. Times series of proportion of snails that were crawling, floating, sinking and burying (+, o, * and $\square$, respectively) in microcosms exposed to light compared to computed results from behaviour model (full, dotted, dashed and dashed-dotted lines, respectively).

Fig. 8. Times series of proportion of snails that were crawling, floating, sinking and burying $(+$, o,$*$ and $\square$, respectively) in microcosms exposed to darkness, compared to computed results from the behaviour model (full, dotted, dashed and dashed-dotted lines, respectively). 
Figure 1

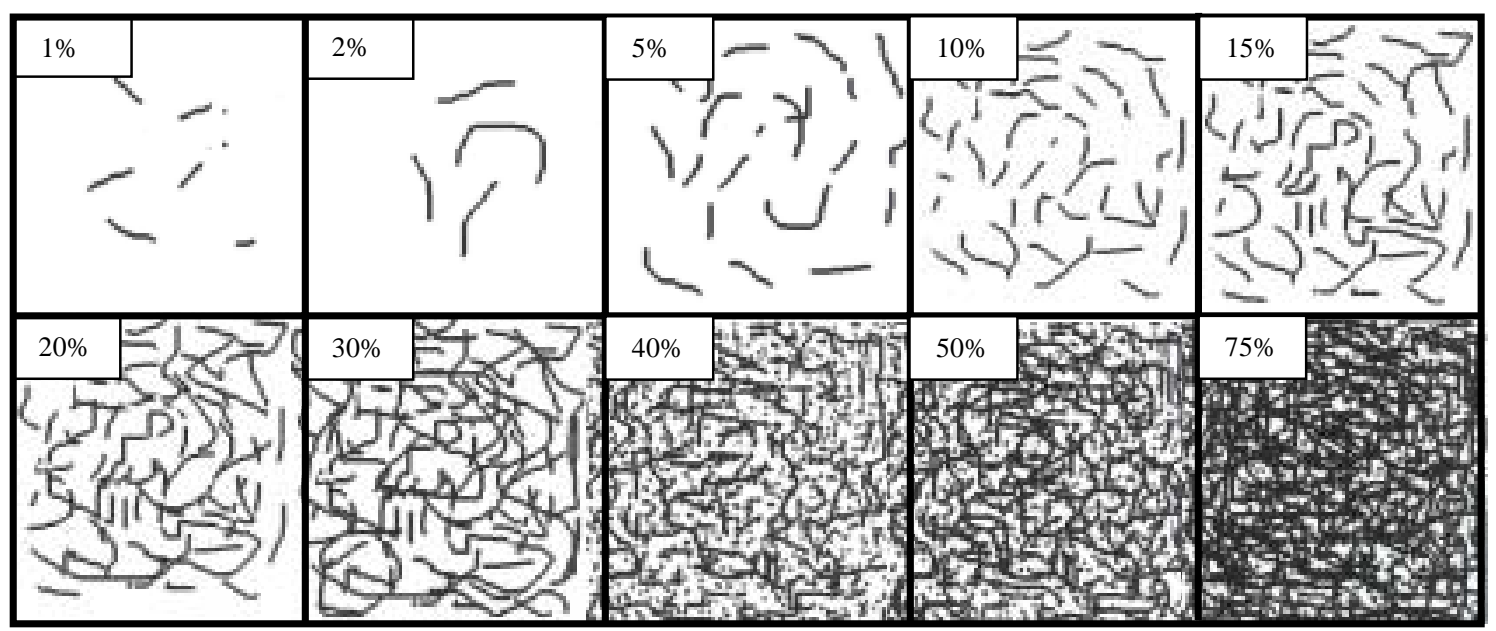


Figure 2

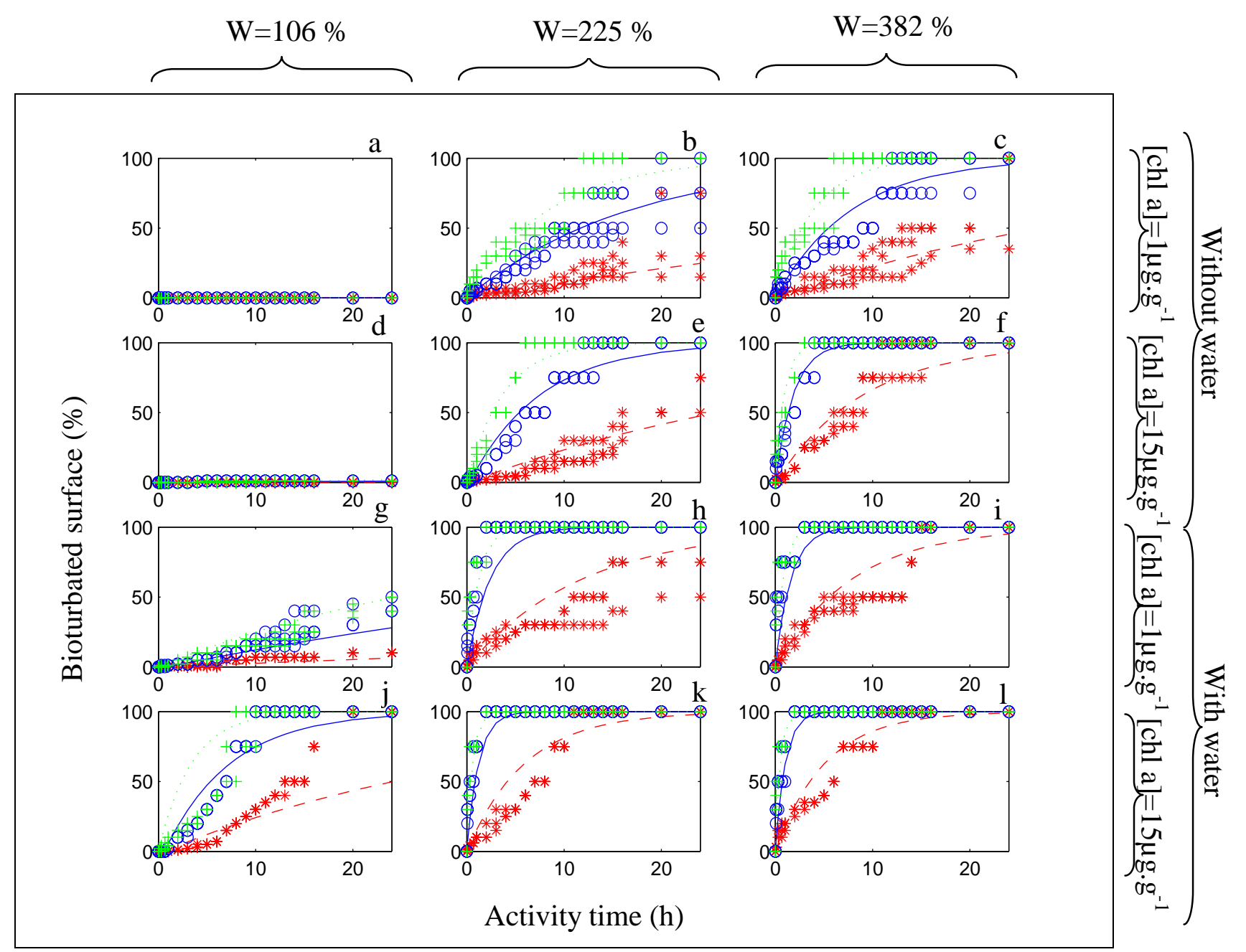


Figure 3

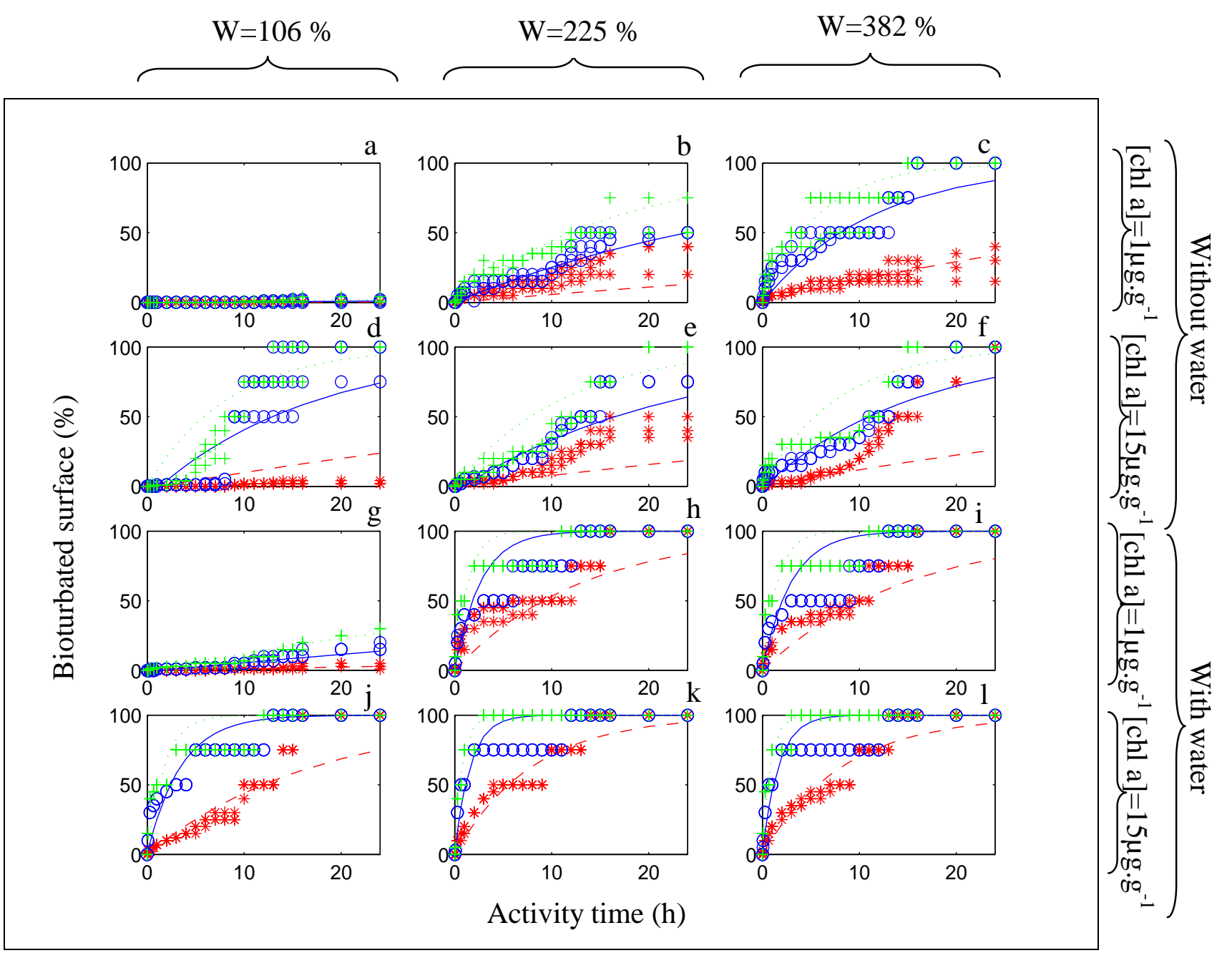


Figure 4

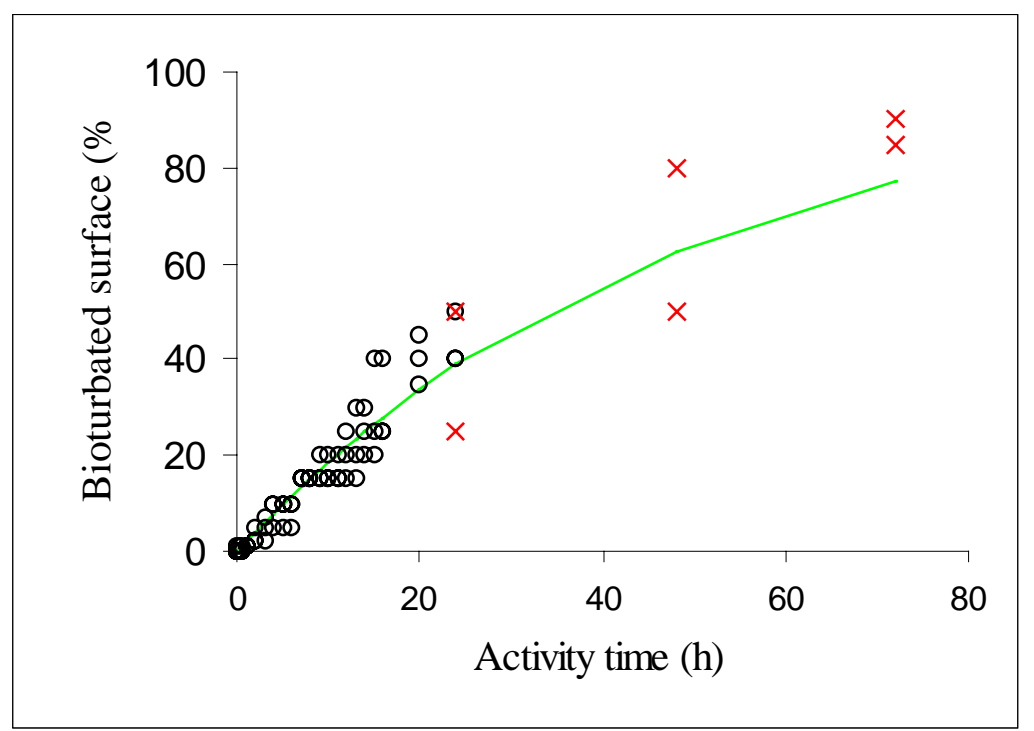


Figure 5
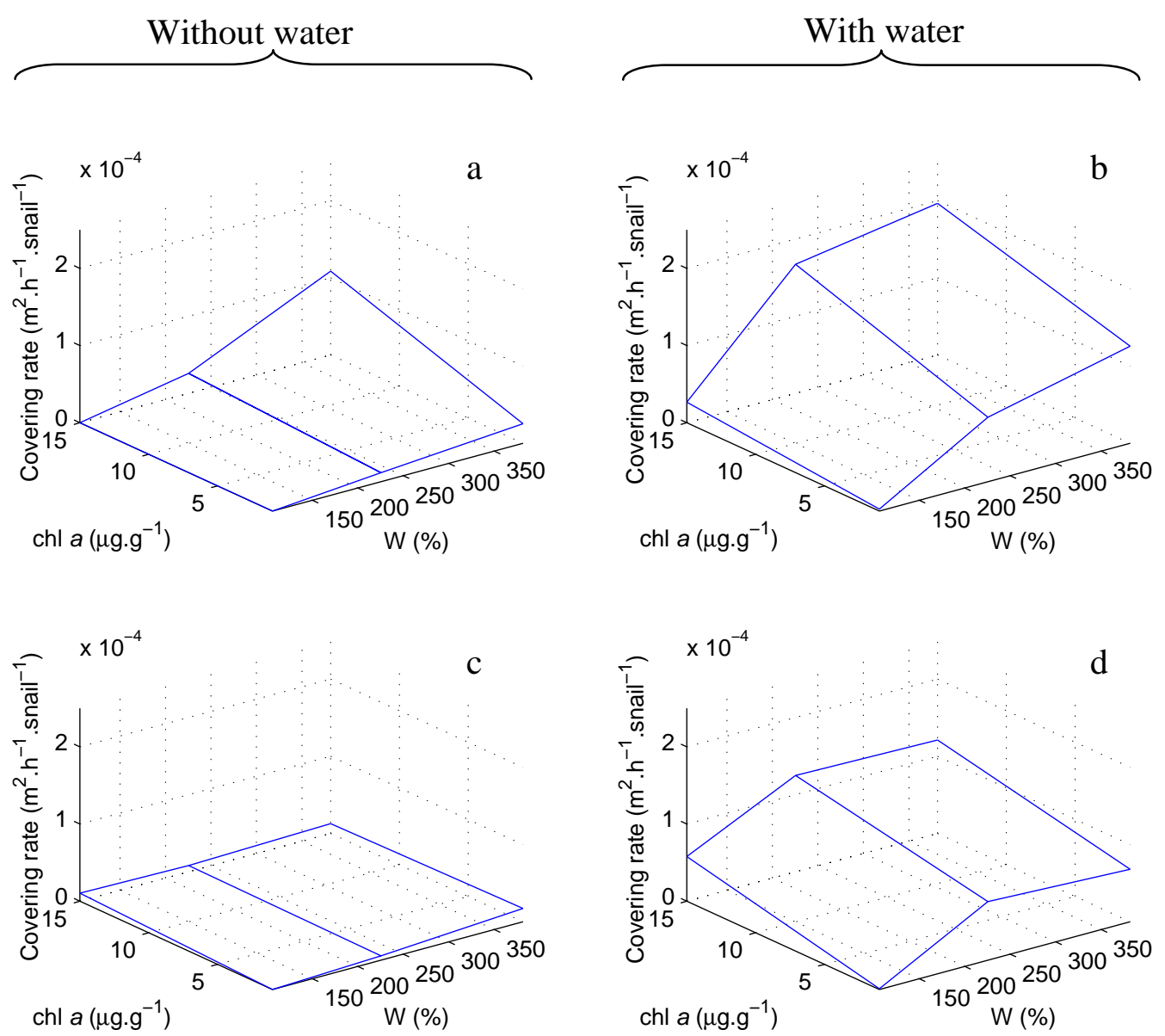
Figure 6
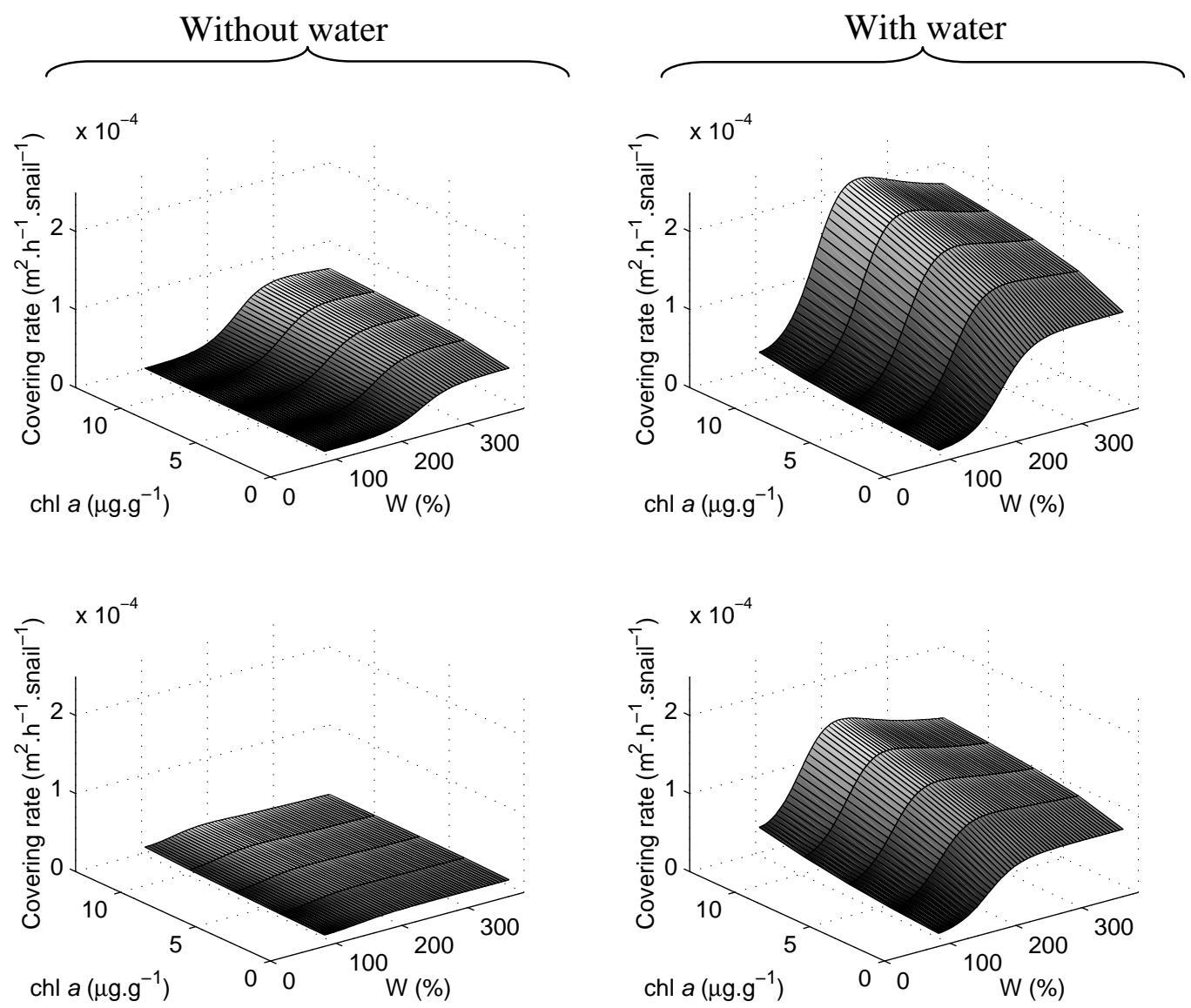
Figure 7
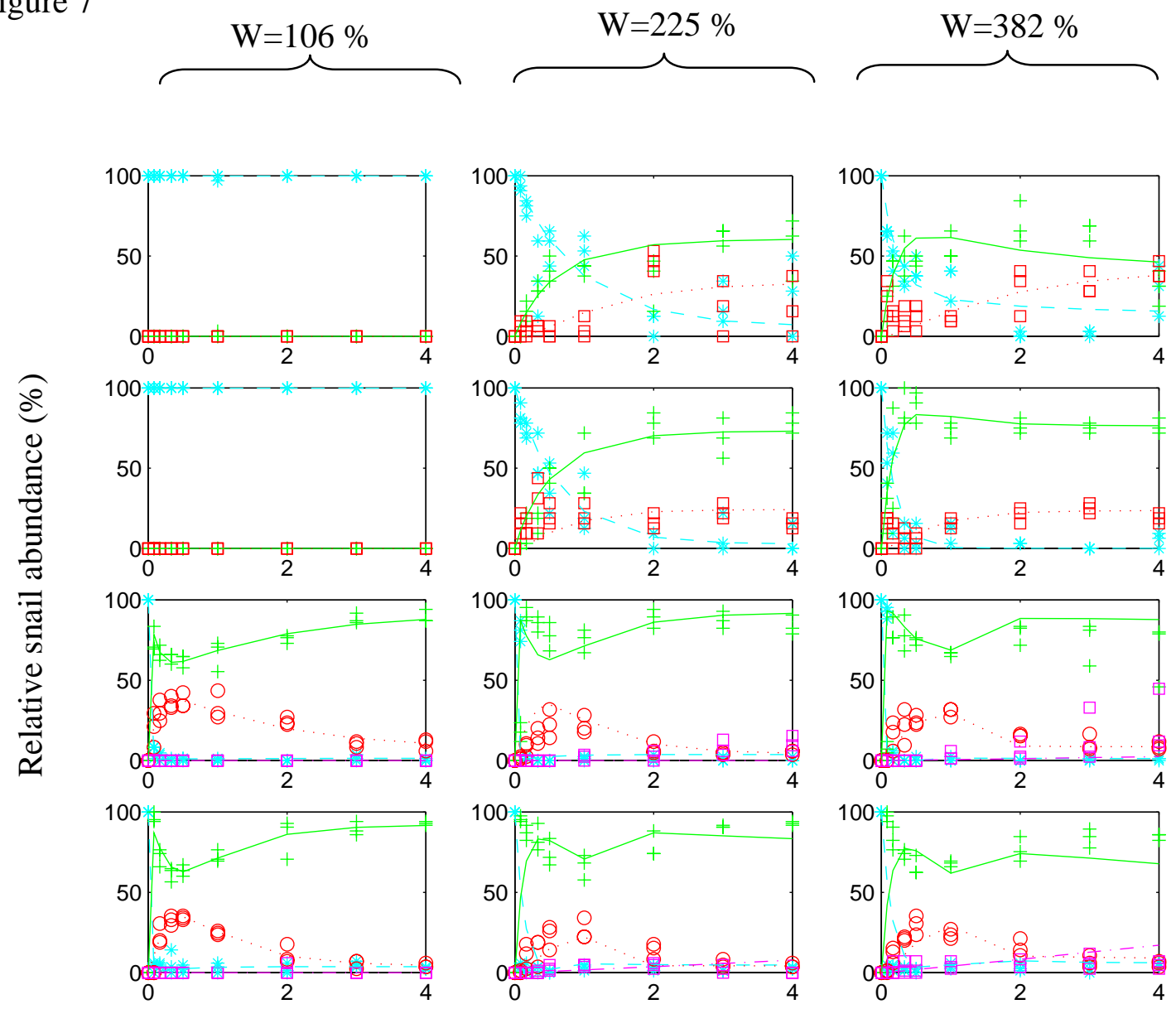

Activity time (h)

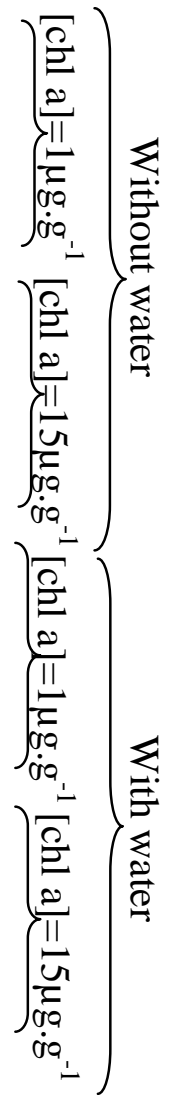


Figure 8
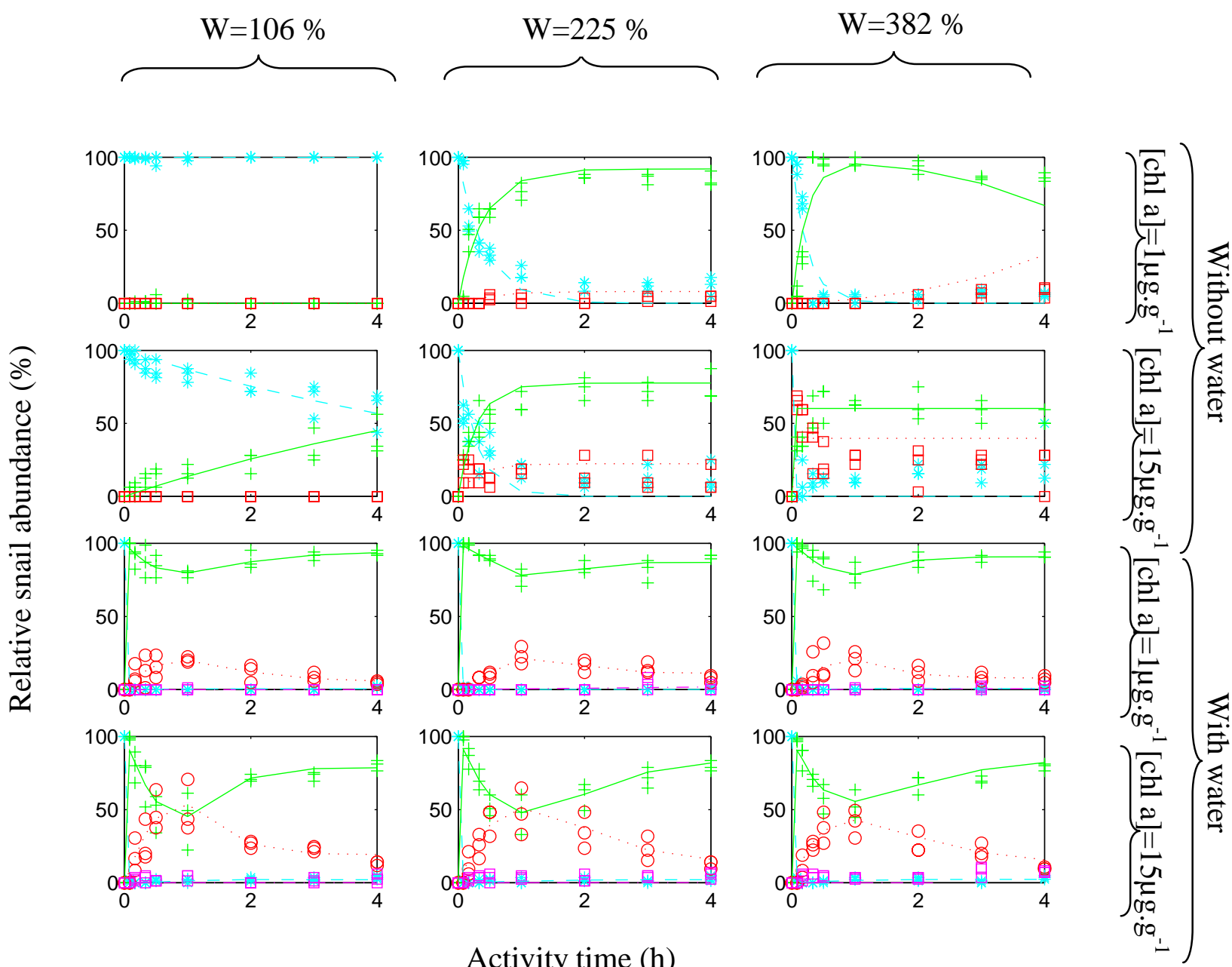

Activity time (h) 